\title{
Neurological findings in autosomal dominant polycystic kidney disease
}

\author{
Demet Yıldız ${ }^{1}$, Abdülmecit Yıldız²® \\ ${ }^{1}$ Department of Neurology, University of Health Sciences, Bursa Yüksek Ihtisas Training and Research Hospital, Bursa, Turkey \\ ${ }^{2}$ Department of Neurology, Uludăg University School of Medicine, Bursa, Turkey
}

DOI: $10.18621 /$ eurj.379970

\begin{abstract}
Objective: Autosomal dominant polycystic kidney disease (ADPKD) mainly affects the kidneys, but other abnormalities like intracranial aneurysms (ICAs) are not uncommon. In this study, we aimed to investigate retrospectively frequency of ICA and other neurological abnormalities in ADPKD patients.

Methods: One hundred and forty patients with ADPKD who did not receive replacement therapy and followedup at outpatient clinic were evaluated.

Results: The mean age of the patients was $43.4 \pm 13$ years and mean glomerular filtration rate was $87 \pm 15$ $\mathrm{ml} / \mathrm{min}$. ICA was detected in four $(2.8 \%)$ patients. Three patients were from the same family. Thirteen $(9.3 \%)$ patients had magnetic resonance angiography due to their family stories, but aneurysm was not seen in them. Conclusion: Individuals with ADPKD who have a history of aneurysm or hemorrhage in their family should be screened for aneurysm due to mortality and risk of recurrent rupture.
\end{abstract}

Keywords: Autosomal dominant, polycystic kidney disease, intracranial aneurysms, arachnoid cysts

Received: January 17, 2018; Accepted: February 12, 2018; Published Online: April 12, 2018

A utosomal dominant polycystic kidney disease (ADPKD) is a genetic systemic disease that characterized by cysts in kidneys and other organs like liver, pancreas, brain and vascular bed. The gene that mostly (in $85 \%$ of the cases) causes the disease is polycystic kidney disease 1 (PKD1) gene on the short arm of chromosome 16 (16p13.3). In 15\% of the cases, polycystic kidney disease 2 (PKD2) gene on the long arm of chromosome 4 (4q21) results in ADPKD. Both genes are pleiotropic and influence many phenotypic characteristics. For instance, abdominal hernias, mitral valve prolapse, aorta dilatation and intracranial aneurysms (ICAs) can be observed clinically in the ADPKD cases. Frequency of ICA varies depending on the family history and was reported to change between
$6 \%$ to $20 \%[1,2]$. Arachnoid cysts $(8 \%)$ and meningeal cysts $(2 \%)$ are other structural abnormalities of central nervous system (CNS) [3, 4]. The most feared clinical picture of ICA is rupture. Although localization, size and rupture story determine prognosis, there is no sufficient data about this issue in ADPKD [5]. It was reported that rupture risk of ICA increases fivefold in ADPKD patients compared to overall population. Family clustering of ADPKD patients with ICA story is apparent, but the presence of ICA among the family members who have the disease is heterogeneous. Besides, the frequency of ischemic stroke is expected to rise in ADPKD cases because of the increased cardiovascular risk. In this study, ADPKD patients were investigated with regard Address for correspondence: Demet Yıldız, MD., University of Health Sciences, Bursa Yüksek Ihtisas Training and Research Hospital, Department of Neurology, Bursa, Turkey 
to CNS abnormalities. Such abnormalities detected with imaging methods were analyzed as well.

\section{METHODS}

One hundred and forty patients who were conclusively diagnosed with ADPKD based on the family story, clinical findings and imaging methods and consulted to outpatient clinic of Uludağ University Scool of Medicine Nephrology Department were evaluated retrospectively in the study. The patients who underwent renal replacement therapy were excluded from the study, since they would not be followed-up at outpatient clinic. Ultrasound criteria suggested by Pei et. al. [6]. were used as diagnosis criteria of ADPKD. Over the course of routine outpatient clinic controls, all of the patients were investigated with regard to possible extrarenal findings, comorbid diseases, smoking history, family history of sudden death, presence of ICA and history of cerebrovascular disease. All of the patients with ICA story in family have been screened with magnetic resonance angiography. The cases that contain aneurysm were consulted to Neurosurgery department.

\section{Statistical Analysis}

As part of statistical analysis, descriptive analyses were performed with SPSS version 22. Variables were given as mean \pm standard deviation.

\section{RESULTS}

The mean age of the patients was $43.4 \pm 13$ years. There were 61 males and 79 females. Sixty-eight percent of the patients did not have smoking history. Hypertension was not detected in $33.6 \%(\mathrm{n}=47)$ of the patients. Of the whole group, $44.3 \%(n=62)$ had controlled hypertension and $22.1 \%(\mathrm{n}=31)$ had uncontrolled hypertension. Fifty-five (39.3\%) patients were found to have liver cyst which was the most common extrarenal finding (Mean age: $47 \pm 12$ years, 36 females, 19 males). Mean glomerular filtration rate was $87 \pm 15 \mathrm{ml} / \mathrm{min}$. In terms of neurological findings, ICA was seen in four $(2.8 \%)$ patients. The aneurysms detected were saccular with a mean diameter of 4.5 $\mathrm{mm}$. In three patients, they were located on the right and left middle cerebral artery. One patient had aneurysm on posterior inferior cerebellar artery (PICA). This patient who was determined to have 3.5 $\mathrm{mm}$ aneurysm on the left and $4.5 \mathrm{~mm}$ on the right admitted to the hospital due to bleeding stroke. He died within one month following the operation. Of other three patients, two underwent an operation in which elective clamp was placed, and one had clamped after hemorrhage. Follow-up of these three patients, who were operated electively or emergency have shown no sign of neurological deficiency. Thirteen $(9.3 \%)$ patients had magnetic resonance angiography due to their family story of ICA, but no aneurysm was detected. With respect to other neurological findings in history, one patient had subdural hematoma, two patients had arachnoid cyst and two patients had epilepsy. Oligodendroglioma was reported (WHO grade 2) in a patient with epilepsy history in frontal region. The patient had postoperative radiotherapy and followed-up without any neurological deficiency. As part of the investigation about cerebrovascular disease, only one patient was detected to have a story of ischemic stroke. Two patients were examined because of headache. Pituitary macroadenoma was observed in one patient, but the lesion with spontaneous shrinking size was interpreted as pituitary cyst. Other patient was diagnosed with migraine.

\section{DISCUSSION}

In our series, aneurysm frequency of ADPKD patients followed-up was lower than that of literature. However, compared to overall population, it was supposed to be higher. This finding may result from the exclusion of the patients who had renal replacement therapy [7]. The findings such as age of onset, hypertension and uremia which are not specific to the disease may improve cerebral hemorrhage risk. It is consistent with literature that the patients who were determined to have aneurysm rupture and asymptomatic aneurysm were in the same family. Intracranial vascular imaging is essential especially for these patients with story of ICA rupture. In literature, it is reported that ADPKD patients with ICA rupture had a mortality rate of $50 \%[5,7,8]$. If ADPKD patients whose genetic penetrance are $100 \%$ 
Table 1. Type and location of intracranial aneurysm

\begin{tabular}{|c|c|c|c|c|}
\hline Cases & Initial presentation & Location & Diameter (mm) & Outcome \\
\hline 1 & $\begin{array}{l}\text { Subarachnoid } \\
\text { hemorrhage }\end{array}$ & Left and right PICA & $5.5 / 3.5$ & Death \\
\hline 2 & $\begin{array}{l}\text { Subarachnoid } \\
\text { hemorrhage }\end{array}$ & Anterior & 3 & $\begin{array}{c}\text { at follow-up } \\
\text { no neurological deficit }\end{array}$ \\
\hline 3 & Elective surgery & Anterior & 35 & $\begin{array}{c}\text { at follow-up } \\
\text { no neurological deficit }\end{array}$ \\
\hline 4 & Elective surgery & Anterior & 3 & $\begin{array}{c}\text { at follow-up } \\
\text { no neurological deficit }\end{array}$ \\
\hline
\end{tabular}

PICA $=$ posterior inferior cerebellar artery

had family stories of sudden death, they can be investigated with regard to presence of ICA. This slowly progressive disease and the emergence of renal failure after the fifth decade make us think that premature death cases seen in the families of patients may result from ICA rupture. In line with this observation, the aneurysm rupture in ADPKD is experienced at a younger age compared to overall population [9]. In general, ICAs seen in ADPKD cases are detected in anterior circle of Willis [3]. In our study, the aneurysms determined in all cases, except one were in the anterior circulation. In a recent meta analysis which evaluated ADPKD with 563 aneurysms, mean diameter of non-ruptured aneurysm was $4.4 \mathrm{~mm}$ and the middle cerebral artery was the main location among half of the patients [8]. In three of our patients, the involvement location was the right and left middle cerebral artery and the diameter of aneurysm was lower than literature (Table 1). There was only one posterior circulation aneurysm that located at PICA, was died. Different aneurysm location of that patient who was in the same family with other two patients make us think that rupture risk may differ despite the presence of aneurysm in the same family. In a case in which pituitary macroadenoma was detected and hormone profile is normal, diameter of adenoma shrank and the lesion was considered as a cyst later. Therefore, we speculated that most of the extrarenal findings in those patients may be associated with PKD1 gene or PKD2 gene.

\section{CONCLUSION}

In conclusion, our results confirm that ICA bleeding in ADPKD patients tends to cluster in families and family history is so important and can provide invaluable information about rupture risk.

\section{Conflict of interest}

The authors disclosed no conflict of interest during the preparation or publication of this manuscript.

\section{Financing}

The authors disclosed that they did not receive any grant during conduction or writing of this study.

\section{Acknowledgments}

We thank Prof. Hasan Kocaeli, M.D., Faculty Member in Neurosurgery Department, and his team who performed intracranial aneurysm operations.

\section{REFERENCES}

[1] Torres VE, Harris PC, Pirson Y. Autosomal dominant polycystic kidney disease. Lancet 2007;369:1287-301.

[2] Chebib FT, Torres VE. Autosomal dominant polycystic kidney disease: core curriculum 2016. Am J Kidney Dis 2016;67:792-810.

[3] Luciano RL, Dahl NK. Extra-renal manifestations of autosomal dominant polycystic kidney disease (ADPKD): considerations for routine screening and management. Nephrol Dial Transplant 2014;29:247-54

[4] Leung GK, Fan YW. Chronic subdural haematoma and arachnoid cyst in autosomal dominant polycystic kidney disease (ADPKD). J Clin Neurosci 2005;12:817-9.

[5] Belz MM, Fick-Brosnahan GM, Hughes RL, Rubinstein D, Chapman $\mathrm{AB}$, Johnson AM, et al. Recurrence of intracranial aneurysms in autosomal-dominant polycystic kidney disease. Kidney Int 2003;63:1824-30.

[6] Pei Y, Obaji J, Dupuis A, Paterson AD, Magistroni R, Dicks E, et al. Unified criteria for ultrasonographic diagnosis of ADPKD. J Am Soc Nephrol 2009;20:205-12.

[7] Xu HW, Yu SQ, Mei CL, Li MH. Screening for intracranial aneurysm in 355 patients with autosomal-dominant polycystic kidney disease.

Stroke 2011;42:204-6. 
[8] Cagnazzo F, Gambacciani C, Morganti R, Perrini P. Intracranial aneurysms in patients with autosomal dominant polycystic kidney disease: prevalence, risk of rupture, and management. A systematic review. Acta Neurochir (Wien) 2017;159:811-21.

[9] Schrier RW, Belz MM, Johnson AM, Kaehny WD, Hughes RL,
Rubinstein D, et al. Repeat imaging for intracranial aneurysms in patients with autosomal dominant polycystic kidney disease with initially negative studies: a prospective ten-year follow-up. J Am Soc Nephrol 2004;15:1023-8. 